\title{
in Kritiese bespreking van Roskam se siening van apartheid as grondslag van die Suid-Afrikaanse samelewing
}

\author{
(Roskam: Apartheid en Diskriminasie)
}

Segregasie is al deur vele ondersoekers histories tot 'n tradisie uit die stigtingsjaar 1652 met die aankoms van Jan van Riebeeck herlei. Roskam sien dit egter as "n heleid wat veel later aanvaar is. Hy sien dit as beleid wat bepaalde groepe van die bevolking as 'n politieke eenheid, kragtens "I sosiale hiërargie, van mekaar wil afskei, isoleer. Dit is vir hom duidelik dat die politieke eenheid van Ordinansie 50 van 1828 nooit werklikheid geword het nie, en die tradisie van blanke heerskappy pas vir hom as beleid beter in die huidige situasie as segregasie. Roskam is dan van oordeel dat ... white supremacy" daarom die juiste en omskrywende betekenis van segregasie is.

\section{A. Verduideliking.}

Om die beleid van apartheid as diskriminerende grondslag vir die Suid-Afrikaanse samelewing uit te wys, bedien Roskam hom van historiese uitsprake en trek daarmee die historiese lyn van die apartheidsgedagtegang vanuit die vorige eeu tot in die huidige situasie.

\section{(a) Historiese oorsig.}

i. Uit die vorige eeu is dit veral die segregasiebeleid van dr. Philip in Kaapland, en Shepstone in Natal, wat die aandag geniet. Dit sou egter foutief wees om hulle die grondlêers van die tradisionele segregasiebeleid te noem. Eersgenoemde liet slegs bedoel om die nie-blankes teen blanke oorheersing te beskerm, en het nie gemeen om 'n permanente oplossing vir 'n vreedsame verhouding tussen hlank en nie-blank daar te stel nie, terwyl laasgenoemde, teri spyte van sy ideaal van sosiale en politieke gelykheid, in sy ..reserve policy" die grondslag vir apartheid gelê het. Jie tydelike en beskermende maatreëls het dus blywende instellinge geword.

Die feit dat die setlaars hierdie instellinge van segregasie verwerp het, hewys volgens Roskam die stelling dat segregasie nie die tradisionele beleid uit die tvdvak 1652 is nie, maar van veel later datum. Daarom 
moet die bevinding van die Tomlinsonverslag in hierdie verband as onjuis vall die hand gewys word.

ii. Die atmbeveling van dic 19)3-ondersoek dat grond vir Bantoes gereserveer moet word, vorm die grondslag ran die segregasielseleid in hierdie eeu. Setdert Unie vorm die heginst van segregasie 'n grondliggende faktor in die Suid-A frikaanse samelening.

iii. Voorts word hirrdic diskriminerende grondslag laaie duidelik weelgegee in die politieke standpunl van die leiers: Genl. Hertzog het grondreservering vir nic-blankes so vroeg as 1913 hepleit, en dit het later 'n integrale ded van dic Hertzog-Regering se wetgewing gevorm. Die "Nuturelle Trust en Lamd Wel” van 1936 gee duidelik uitdrukking aan die segregasieleleid van die Hertzog-Smuts-Regering. Hierteenoor het genl. Smuts nie altyd in konsekwente stem laat hoor nie. In 1917 het hy apartheid lussen hlank en nie-blank in Londen hepleit, en in 1926 het hy dit as Opposisieleier in die Unic-Parlement teengestaan. In 1942 het hy dit weer 'n onrealistiese beleid genoem en in 1947 is die prinsipe van apartheid weer duidelik onderstreep.

iv. Die Botha-Regering het segregasie so vroeg as 1913 as beleid goedgekeur, en die Arheidersparty so vrocg as 1912. Dit moet dus duidelik gestel word dat segregasie na 1913 slatsheleid was, en die ongelyke lochandeling van blank eti nie-blank is per wetgewing vasgelê.

v. Die vrysinnige Hoernlé het dit beklemtoun dat segregasie sy oorspronklike hetekenis van heskerming vir die nie-hlankes verloor het, en daarom het hy segregasir as rasse-ideaal van bloedsuiwerheid vir hlankes, eksklusiewe stemreg vir blankes, politieke oorheersing van niehankes, en 'n verydeling van die idcaal van eenheid en gelykheid tussen blank en nie-blank in dic Suid- $\Lambda$ frikaanse samelewing veroordeel.

vi. Met die bewindsverandering van die Malan-Nasionale Party gedurende 1948 het daac 'n radikale verskerping van die apartheidswetgewing ingetree. Die liggan-rapport het die situasie waarin die Nasionale Party die hewind oorgeneem het as volg heskrywe: Totale segregasie is geheel onprakties, en die beweging van nic-hlanke arheiders na die stad as 'n ekonomiese noodsaaklikheid, en die gevestigde nie-blankes in stadsgebiede gee 'n permanente nie-blanke bevolking in hlanke gebiede. Teen hierdie agtergrond het die Nasionale Party die bewind met die belofte van 'n fundamentele verandering en verskerping in die apartheidsbeleid oorgeneem. Hierdie helofte het die verdere apartheidswetgewinge bepaal.

Met hostande historiese feite het Roskam dit duidelik gestel, dat apartheid of die heleid van , white supremacy" die duidelike gevolg of uitvloeisel van die tradisionele segregasiel,eleid is, en dat die apartheidsheleid die grondslag van die Suid-Afrikaanse samelewing vorm. Die huidige situasie is dus die gevolg van diskriminasie, ongelyke behandeling van gelyke staatsburgers. 


\section{(h) Apurtheid omskrywe.}

Dic woord sell is volgens E. G. Jansen so vroeg as 1936 in politieke sin gehruik, terwyl dit eers so laat as 1950 in die Woordeboek omskrywe is: Apartheid is 'n politieke neiging gebaseer op die beginsels van differensiasie in oreenstenıming met rasseverskille en/of kleur teenoor gelykheid; (1) die handhawing en voortsetting van die verskillende kleurgroepe met hrhoud en ontwikkeling van hul eie aard, tradisies en bekwaamheid teonour integrasie.

Dit is dus 'n politieke rigting, beleid, wat rasseskeiding as doelstelling het. Dit veronderstel ajarte geriewe, soos aparte woonbuurtes, publinke voorregtc, vervoes, aparte politicke regte ens., ens., vir die underskeje kleurgroepe. Die einddoel van die beleid is dus: territoriale skejding tussen blank en nie-blank. Apartheid beteken dan dat elke kleurgroep, Blankes, Kleurlinge, Asiate en Bantoes uiteindelik hul eie Iuistes sal hesil. Dit stel dus 'n skeiding wat op kleurverskille gebaseer is vir die totale bevolking voor. Apartheid meen skeiding aan die hele lewensfront.

Die voorstelling van algehele apartheid soos deur Hoernlé voorgedra is, was vir die apartheidsleiers, voorstaanders of profete, onaanneemlik, en hulle meen om die geskeie gemeenskappe onder "white trusteeship" te stel. Hierteenoor het dr. Eiselen, die belangrikste teoretikus van apartheid, die gedagte van blanke voogdyskap vermy en sien hy die uiteindelike doel van apartheid in die totstandkoming van aparte selfonderhoudende sosio-ekonomiese cenhede, 'n proses wat oor baie jare sal strek. Die heklemtoning van algehele apartheid wat tot selfregering van die Bantoe in sy cie golied moet lei. soos deur Hoernlé beklemtoon, het die gevolg gelad dat apartheid nie meer in radikale sin beklemtoon is nie.

Die Suid-Afrikaanse Buro vir Rasse-aangeleenthede, SABRA, het dit tot hul voordeel. dat hulle eintlik die inhoud en rigting ann die politieke lıeleid van apartheid gegee het. Iie voordrag van apartheid deur SABRA gaan van die veronderstelling uit dat dit nie op ongelykheid gebaseer is nie. maar op, verskille, en veronderstel 'n beskerming vir die blankes. Jie heginsel van selfhelıoud moet tot gebiedskeiding tussen Europeaan en Bantoe lei. Politieke regte kan aan die Bantoe in sy eie Bantoegebied nie onthou word nie, dit sal immoreel wees. Apartheid is vir SABRA die enigste ,verstandige en terselfdertyd wetenskaplik gefundeerde naturellebeleid" en die teendeel beteken ,totale integrasie cn gevolglike gelykstelling". Die ideaal van SABRA moet dus gesien word in die ontwikkeling van die Bantoetuistes, sodat daar werkvoorsiening gemaak kan word en die Bantoe dit 'n ware tuiste sal vind. Dit sal beteken dat die nie-blankes in die blankegebiede dan na hul eie gebiede 
sal verhuis. Gelyke heregtiging van bank en nie-blank in hul onderskeie gebiede is die einddoel. Dit is volgens Roskam alleen moontlik indien die trekarbeider die behoefte aan nie-blanke arheid in die blankegebied sal vervul, anders is gebiedskeiding onmoontlik. Die grondslag bly dus ongelyk, diskriminerend teenoor die Bantoe.

Die Tomlinson-Kommissie het dit haie duidelik gestel dat die ontwikkeling van die Bantoetuistes 'n absolute vereiste is. Regte en voorregte sowel as dienste en verantwoordelikhede kan nie veel langer van die nie-hlankes weerhou word nie, mar dan in hul eie gebiede. Vir die verwescnliking van die apatheidsheleid sal die grondvoorsiening vir die Bantoetuistes, deur die 1930-wetgewing van genl. Hertzog; nie genoegsam wees nie. Om hierdie probleem die hoof te bied is die TomlinsonKommissie van oordeel dat die Britse gebiede Basoetoland, Betsjoeanaland en Swaziland by dic Republiek ingeskakel moet word, en dat dit dan vir Bantoeluistes ontwikkel sal word. Hierdie siening lê ook in die gesigsveld van dr. Eiselen. Dit beteken dat die blankes enersyds voorherei word om groot opofferinge vir die oplossing van die rasseprobleem te maak, en andersyds beteken dit dat Brittanje die verantwoordelikheid daartoe moet neem.

Die beginsel van diskriminasie, apartheid as beleid van rasseskeiding, dien as grondslag vir die Suid-Afrikaanse samelewing, en is die oorsaak van 'n gevoel van onsekerheid by die nie-hlankes. By alles wat sover gesê is, is dit duidelik dat apartheid 'n heleid van ongelykheid is, en dat dit daarom 'n geval van onsekerheid by die Bantoe skep. Apartheid is die grondslag van 'n ongelyke Suid-Afrikaanse samelewing.

\section{(c) Apartheid as beleid van die Nasionale Party.}

Die Nasionale Party-Regering plaas homself op die veelhesproke beleid van rasseskeiding as oplossing vir rasseverhoudinge. 'n Feitlike situasie wat deur die geografiese en ekonomiese integrasie, die getalsverskille van die verskillende etniese groepe, die rasseverskille en beskawingsverskille gekarakteriseer word. "I Situasie wat op twee rigtings aanwys, t.w. 'n geïntegreerde veelrassige gemeenskap of apartheid met 'n veelheid van rasse-gemeenskappe naas mekaar. Rasse-integrasie is onaanneemlik, want die rasseverskille is fundamenteel aanvaar. Die regerende party gaan van die selfbehoudende voorveronderstelling uit dat die verskillende etniese groepe histories tot 'n hepaalde gebied gekoppel is.

Hierdie teoretiese agtergrond van apartheidsbeleid word deur die volgende beginsels of fundamentele voorveronderstellings gedra: Apartheid beteken nie algehele territoriale skeiding nie; blanke heerskappy moet behoue bly; n veelheid van rassegemeenskappe beteken slegs verdeling van blank en nie-blank met 'n bejerkte outonomie aan die nie- 
hlanke gebiede; die regte van die nie-blanke moet van die ekonomies geintegreerde blankegebiede na Bantoetuislande oorgeplaas word; en die ontwikkeling en gebruikmaking van genoemde regte moet onder 'n blanke baasskap geskied. Hierdie prinsipe of voorveronderstellinge gee die beleid van apartheid, van ongelykheid wat die wenslikheid van die nieblanke aandeel in die huidige ekonomiese posisie steeds wil verleng sonder om gelyke regte in blankegebiede aan die nie-blankes te gee.

\section{Gebiedskeiding.}

Die Nasionale Party hou vol dat totale gebiedskeiding die ideale oplossing vir die rassevraagstuk is, en tog het dr. Dönges in 1959 verklaar dat totale territoriale skeiding "onuitvoerbaar en onprakties" is. Die corspronklike manifes van die Nasionale Party in 1939 het segregasieas heginsel aanvaar, maar van totale segregasie was daar geen sprake nie. Afgesien van die uitvoerbaarheid of nie, bly dit nog 'n vraag of dit 'n oplossing vir die rassevraagstuk is.

Die term apartheid tree sedert 1947 as beleidsrigting van die N.P. (p) die voorgrond, en is deur dr. Jansen met segregasie as beleid van aparte ontwikkeling vereenselwig. Apartheid moet dus gesien word as 'n proses van voortgesette skeiding in alle lewensfere, al sal daar ook geen gebiedskeiding wees nie (aldus dr. Verwoerd). Dit is dus duidelik dat die N.P. geen erns met totale apartheid wil maak nie. Die traagheid om totale gebiedskeiding deur te voer, moet in die feit van die blanke afhanklikheid van nie-blanke arbeid gesoek word, en tweedens omdat totale apartheid dieselfde gevaar as integrasie inhou. Die eis van onafhanklike en aparte Bantocstate dra die kiem van Suid-Afrika se gewisse ondergang. Daarom is die N.P. nie legerig om totale gebiedskeiding vir blank en nie-blank deur te voer nie.

\section{Blanke heerskappy.}

Die ideale oplossing vir die rassevraagstuk, totale apartheid, kan slegs onder blanke heerskappy uitgevoer word. Dr. Malan het tydens die N.P.kongres te Bloemfontein, Suid-Afrika as 'n "witmansland" onder blanke heerskappy, d.w.s. „blanke voogdyskap” genoem. Blanke heerskappy met die soewereine blanke leierskap van die Europeane is dus 'n grondliggende leginsel in die beleid van apartheid, en is in beginsel in die konstitusie van die Unie opgeneem en word steeds deur die Nasionale Party-Regering gehandhaaf. Hierdie versekering is by herhaling deur Malan, Strijdom en Verwoerd gegee. Die ekonomiese en kulturele meerderwaardigheid van die blanke moet bly, en om dit te verseker moet "die reg om te stem in ons hande bly". - (Strijdom). 
Die onderliggende beginsel om die nie-blanke te oorheers en daardeur die blanke baasskap te verseker, is nog steeds die beginsel waardeur die ,white man's control" beveilig word. Selfs die intensifering van die apartheidsheleid deur Verwoerd, met sy beleidsrigting van aparte ontwikkeling van die Bantoetuislande met die oog op selfregering, hou nog steeds die belofte van blanke oppergesag in. Blanke kontrole of baasskap is 'n vereiste vir rus en vrede, daarom kan die mooi woorde van voogdyskap en beskermheer niks anders beteken as 'n permanente oppermagtigheid van die blanke in Suid-Afrika nie. Die diskriminerende grondslag van apartheid as beleid van rasseskeiding, lê aan die grondslag van die Suid-Afrikaanse samelewing en daarmee ook aan die wortel van die ontwikkeling van die Bantoetuislande.

\section{Veelheid van rassegemeenskappe.}

in Veelheid van onafhanklike rassegemeenskappe (state), is nie die heleid van die Nasionale Regering nie, want die blanke kontrole moet behou word. Verder is daar 'n onwilligheid om die reservate ten volle te ontwikkel. want die hlankes weier om die voordele van nie-blanke arbeid prys te gee. Die geografiese eis van apartheid word maar effens toegelig; en hoewel daar haie oor die terugkeer tot die reservate gepraat word, tog gaan die toevoer van trekarbeid na blanke gebiede nog steeds voort. Die Malan-Regering het dit ook duidelik gestel dat apartheid deur die behoefte aan nie-blanke arbeid gelei sal word.

Die beleid van nie-blanke rescrvate binne die ramwerk van apartheid, beteken niks meer as 'n voortsetting van die tradisionele beleid om regti en voorregte aan nie-blanke te weerhou nie. Dit is 'n beleid wat die aanklag van diskriminasie deur die weerhouding van 'n volwaardige Suid- $\Lambda$ frikaanse burgerskap aan die nie-blankes wil verbloem. Die reservate sal dus dien as ' $n$ permanente tuiste vir die nie-blankes om dan as trekarbeider tydelik na die stede en ander blankegebiede te verhuis. Die teorctiese beleid van territoriale skeiding is daarom ' $n$ klug en beteken slegs die voortsetting van blanke heerskaply, selfs in die nie-blanke gebiede.

\section{Bantoetuislande.}

Die teoretiese beleid van Bantoetuislande gee voor dat die Bantoe sy regte en voorregte in dic Bantoetuisland sal ontvang en dat hy as trekarbeider in die blankegebiede slegs 'n tydelike tuiste sal vind. Dit gee die eienaardige verskynsel dat nie-blankes as trekarbeiders permanent in blankegebiede sal kan woon sonder dat hulle enige burgerregte kan kry. Die Bantoe-arbeider wat in die stadsgebied woon, sal sy regte in die land van sy geboorte (stadsgebied) verbeur om dit te ontvang in 'n land 
wat baie van hulle nog nie eens gesien het nie. Dit word voorgegee dat die teenwoordigheid van nie-blanke trekarbeiders in blanke gebiede 'n opoffering vir die blankes is, terwyl dit 'n vernederende posisie van die nie-blanke is.

Die tuisland-beleid is slegs 'n teorie wat die bevoorregte posisie van die blanke steeds wil kontinueer en dic „white supremacy” as tradisionele heleid wil handhaaf.

\section{Die ontwikkeling van Bantoeluislande onder blanke heerskappy.}

Dr. Verwoerd het dit tydens die bespreking van die Tomlinsonverslag duidelik gestel, dat daar in die jaar 2000 nog meer as sesmiljoen Bantoes in hlankegebiede sal woon. Die trekarheider sal daarom in permanente gebruik van die blanke wees. Die vraag na nie-blanke arbeid sal dus altyd die hepalende faktor wees, en die ontwikkeling van Bantoetuislande moet daarom onder blanke kuntrole geskied. Die fabrieke op die grensgebiede sal volgens Verwoerd die surplus nie-blanke arbeid opneem. Die werklike ontwikkeling van die Bantoegebiede sal dus nog steeds in blanke hande bly, slegs 'n klein gedeelte sal aan nie-blankes oorgelaat word.

Die "border-industrial" ontwikkeling bewys die feit dat die N.P. nie veel erns met die ontwikkeling van die Bantoetuislande het nie. Blanke helange sal altyd die deurslag gee. Dit is duidelik dat die onafhanklikheid van die selfregerende Bantoetuislande nie geduld sal word nie, daarom sal die selfregering slegs plaaslik van aard wees. Die hele benadering van die apartheidsbeleid, die territoriale skeiding, deur die ontwikkeling van die Bantuereservate is 'n klug, 'n blote stuk bedrog. Dit is madr net 'n verbloeming van die blanke heerskappy wat die Bantoe in die vernederende posisie van ondergeskikte afhanklikheid wil hou. Die teenwoordige materiële, politieke, en ekonomiese bevoorregte posisie van die blanke, die tradisionele beleid van blanke heerskappy moet beveilig bly. Selfs die ontwikkeling van die Bantoetuislande dui beslis op diskriminasie.

\section{(d) Apartheid as beleid beoordeel.}

Dr. Malan het dit duidelik gestel dat apartheid 'n negatiewe kant lıet, maar nie onderdrukking beteken nie. Hy plaas die beleid van apartheid op die beginsel van voogdyskap, terwyl dr. Verwoerd van aparte ontwikkeling praat as 'n Christelike voogdyskap deur die Europeane. Beide sien appartheid dus as 'n beleid van voogdyskap, 'n beleid van ondergeskiktheid van dic nie-blanke. 
Die taak van die voog, volgens N.P.-standpunt is, om alle invloede wat moontlik die identiteit van die Bantoe as nasionale eenheid kan ondermyn, af te weer, en om geleenthede te skep vir die etniese groepe om volgens eie aard, onder invloed van die Christelike beskawing tot 'n selfstandige nasionale groep te ontwikkel. Die geskiktheid en arbeidsvermoë word deur die natuurlike aanleg en vaardigheid bepaal. Dit is juis die gronddwaling in die apartheidsbeleid.

Apartheid is gebaseer op verskille en gee geen waarborg vir gelyke beregtiging nie. Die ontwikkeling volgens eie aard veronderstel dus nie gelykheid nie, maar ongelykheid. Minister De Wet Nel het dit dan ook duidelik gestel dat dit nie 'n beleid van gelykheid is nie. Die naturel sal sy regte as naturel ontvang. Daarom moet die fundamentele begrip, verskille, slegs as versagtende term vir ongelykheid gesien word. Die ,naturel" kan dus volgens N.P.-standpunt nooit 'n beskaafde geleerde Bantoe met die geregverdigde eis van gelykheid wees nie. Die geregverdigde eis van gelyke regte moet dus sover moontlik na die toekoms verskuif word. Blanke heerskappy, die dominering van die nie-blankes deur die blankes, is en bly 'n grondheginsel in die beleid van die Nasionale Party. Die plegtige versekering dat die naturelle 'n regverdige aandeel in die landsadministrasie, kragtens aparte ontwikkeling sal kry, is deur die beleid van apartheid geloënstraf. Apartheid meen volgens Roskam die waarborg vir 'n permanente heerskappy van blankes oor nie-blankes.

Die dubbelsinrige siening van geregtigheid is 'n verdere gronddwaling van die beleid van apartheid. Regverdigheid teenoor nie-blanke is altyd ondergeskik aan die regverdigheid teenoor blankes. In hierdie gedagtegang veronderstel ontwikkeling van die Bantoetuislande volgens die Bantoe se eie aard, bekwaamheid en kapasiteit, nie ontwikkeling tot gelykheid nie, maar voortgesette ondergeskiktheid, daarom meen regverdigheid die beskerm van blanke regte, en diskriminasie bly die grondslag van aparte ontwikkeling.

Totale gebiedskeiding, of apartheid, stoel op die wortel van ongelyke behandeling van gclyke staatsburgers, daarom is dit 'n bcleid van diskriminasie. Territoriale skeiding as oplossing van die rassevraagstuk beteken dus die voortsetting van ,white supremacy". Die ongelyke boedelverdeling tussen blank en nie-blank bewys die beplanning van 'n voortgesette afhanklikheid wat die Bantoe in die vernederende posisie wil vaspen. Ten spyte van die waarborg dat apartheid nie onderdrukking beteken nie, moet apartheid as 'n onderdrukkingsbelcid van dic hand gewys word. Apartheid is 'n beleid van diskriminasie, 'n ongelyke behandeling van gelykes en dit lê aan die grondslag van die Suid-Afrikaanse samelewing. 


\section{B. Kritiese bespreking.}

Die oordcel van Roskam, dat diskriminasie die grondslag van die apartheidsheleid is, en dat hierdie ongelyke beleid aan die grondslag van die Suid-Alrikaanse samelewing lê, kan op tweërlei wyse - alles afhangendi van die beoordelaar se uitgangspunt - krities bespreek word. Die humanis wat sy uitgangspunt in die gelykheidsdogma van die humanisme neem, sal dit gunstig as in afdoende en verdoemende antwoord aan die apartheidsvoorstanders beoordeel. Dit is omvangryk en die dokumentêre bewyse is sterk sprekend in die guns van die gelykheidsdogma wat apartheid graag as strydig met die fundamentele menslike regte en voorregte wil verdoem. Hierteenoor sal die Christelike navorser, wat sy uitgangspunt in die waarheid van die religieuse grondmotief van die Christelike wysbegeerte neem, en daarom Roskam uit die hoek van die Christelike beskawingsleer beoordeel, die bevinding as ongegrond, volgens die onbewese voorveronderstellinge van die humanisme van die hand wys. Die aard van die kritiek sal dus deur die uitgangspunt van die kritikus bepaal word.

(a) Historiese oorsig.

Die historiese oorsig van die ontwikkeling van die segregasie of apartheidsgedagte is seker suiwer volgens die ware verloop. Dit bewys egter geen gemene spel met die nie-blanke nie, maar dit openbaar 'n dinamiese soepelheid in die heleid wat in verantwoordelikheid by die ware behooftes van die nie-blanke wil en kan aanpas. Die gelykheidsdogma van die humanisme is nie in staat om die ongelykheid, kragtens die sondeval en die heerlike ampsherstel in Jesus Christus, die herskepping, te begryp nie. Die sondaarmens, die vervalle heiden, is ongelyk met die herskape Christen en daarom kan blank en nie-blank nie gelyk behandel word nic. Die heidense onontslote kultuur kan tog nie met 'n pennestreep met die Christelike kultuur gelykgeskakel word nie. Die gelykheidsdogma is 'n humanistiese droombeeld wat nie bestaan nie.

Die historiese ontwikkeling en toepassing van die segregasiegedagte is nie 'n stuk bedrog soos Roskam dit wederregtelik bestempel nie, maar dit is 'n Christelike verantwoordelikheid wat voorregte aan die heiden, wat toevallig in kleur verskil, wil gee. $\mathrm{Hy}$ wat die historiese gang van die apartheidsgedagte onhevange, los van die humanistiese gelykheidsdogma, studeer en navors, sal die positiewe grondslag van die segregasie, die gedagte van skeiding tussen blank en nie-blank, spoedig ontdek. Segregasie is ' $n$ beleid wat die onbetwiste ongelyke kultuur, stand en status van blank en nie-blank positief wil benader. 
(b) Aaprtheid omskryue.

Die opset van Roskam se studie was daarop bereken om apartheid as diskriminasie te bewys. Daarom het hy hom slegs by uitsprake en omskrywinge wat die ongelykheidshehandelinge benadruk, bepaal en die positiewe grondslag van apartheid misgekyk. Voordat Roskam diskriminasie kan bewys, moet hy eers die gelykheid as onbetwis hewys. Diskriminasie kan slegs bewys word mits daar regte en voorregte op ongelyke hasis aan gelykes uitgedecl wold. Roskam kan daarom eers diskriminasie hewys wanneer hy beskawingsgelykheid, d.w.s. kulturele en verantwoordelikheidsgelykheid hewys het. Die hevoegdheid om gelyk te wees moet eers by die Bantoe bewys word. Die diskriminasie of ongelykheidsbehandeling wat Roskam deur uitsprake wat die woord omskrywe wou bewys, het dlus jammerlik gevaal.

Die on wetenskaplike uitgangspunt of voorveronderstelling van Roskam het geen diskriminasie bew ys nie, maar het andermaal die valsheidsgrondslag van die humanistiese wetenskap bewys. Die wetenskap wat nie van alle waarheidsgronde wil kennis neem nie, moet noodwendig dwaal. Roskam het gedwaal omdat hy in sy humanistiese vooroordele nie van die ongelykheid in stand en status van blank en nie-blank wou kennis neem nie. Diskriminasie is nic hewys nie. Die ongelykheidshelandelinge rus op die geregverdigde maatstaf van 'n onhetwiste ongelykheid in beskawingsverantwoordelikheid en bevoegdheid tussen blank en nie-blank.

\section{(c) Apartheid as beleid van die N.P.}

Wanneer dit tot die ware wese van die saak $\mathrm{kom}$, die ontleding van die apartheidsbeleid, dan tree die humanistiese onbeholpenheid van Roskam om tot die waarheidsgrond deur te dring, baie sterk op die voorgrond en die navorser begaan twee fundamentele foute: (a) Die beskawingsagterstand van die nie-blanke wat 'n onbevoegdheid en onbetwisbare onverantwoordelikheid in die praktyk gee, word gerieflikheidshalwe links gelaat en (b) die positiewe grondslag van die apartheidsbeleid wat hierdie toestand die hoof wil bied, word deur sy sprekende vooroordeel doodgeskrywe. Roskam het nie getrag om die apartheidsbeleid tot sy wortel te ondersoek nie, maar het gekom om sy humanistiese voorveronderstellinge kragtens sy gelykheidsdogma te bewys. Roskam het die eerste beginsel van die wetenskap, die soek na waarheid en die opheldering van die waarheid, verkrag.

Apartheid is ' $n$ positiewe beleid wat daarop bereken is om die beskaafde Bantoe tot 'n besliste beskawingsverantwoordelikheid te lei. In sy huidige staat is die Bantoe onbevoeg om 'n staatsverantwoordelikheid 
te neem, daarom is die beleid van territoriale skeiding 'n ware Christelike verantwoordelikheid wat die ongelykheidsposisie van die Bantoe besef, en daarom trag om die nie-blanke stelselmatig op te voed en tot verantwoordelikheid in sy eie gebied te lei. Dit is 'n Christelike verantwoordelikheid wat die chaos en diktatuurdwinggelandy van die Midde-Afrikaanse Bantoestate wil onderskep. Dit is 'n Christelike beleid wat die Bantoe stap vir stap tot selfstandigheid wil lei.

\section{i. Territoriale skeiding.}

Omdat Roskam nie die ware positiewe grondslag van die apartheidsbeleid vanweë sy gelykheidsdogma kon opmerk nie, daarom sien hy in die beleid van gebiedskejding 'n onderdrukking of diskriminasie wat dan met die fundamentele regte en vryhede van die mens strydig is. $\mathrm{Hy}$ is nie in staat om die ware ongelykheid, kragtens die dominering van die sondeval in die heidenhart en -kultuur teenoor die ampsherstel in Christus, in die blank-nie-blank verhouding grondig op te merk nie. Daarom is hy nie in staat om die boedelverdeling in die apartheidsbeleid na waarheid te begryp nie. Apartheid wil die kulturele, sosiale en politieke ongelykheid langs die weg van opvoeding en die stelselmatige oordra van verantwoordelikheid in 'n uiteindelike gelykheid in die beleid van territoriale skeiding waar borg. Dit is vir Roskam kragtens sy onwetenskaplike gelykheidsdogma nie aanneemlik nie.

\section{ii. Blanke heerskappy.}

Roskam is ook nie in staat om die beleid van voogdyskap te begryp nie. Kragtens die voorveronderstelling van gelykheid, gelyke boedelverdeling in die huidige sosio-ekonomiese geïntegreerde situasie, skakel Roskam die noodsaaklikheid van 'n blanke, en in die ware sin van die woord 'n beskawingsheerskappy, totaal uit. Vir hom is blank en nie-blanke kultureel, sosiaal en polities gelyk en moet die nie-blanke binne 'n politieke staatkundige eenlieid aanvaar word om politieke verantwoordelikheid saam met die blanke gelykop te deel. Hierdie siening is van alle waarheidsgronde ontbloot, want dic toestand van 'n kulturele, sosiale en politieke ongelykheid staar hom in die werklike situasie in die oë. Ongelykheid in beskawing en daarom in verantwoordelikheid kan en sal slegs deur 'n onwetenskaplike, verdwaasde mens ontken word.

Die Christelike verhouding van voogdyskap, die verhouding van vader tot kind, beskawing tot primitiwiteit, beskaafde tot onbeskaafde, blanke tot nie-blanke, word deur Roskam nie ingesien nie, en hy verkies om kragtens die gelykheidsdogma van die humanisme, nie daarvan kennis te neem nie. Dit het nie gegaan om 'n wetenskaplike ondersoek wat die 
waarheid in die nagevorste waarhede wou ophelder nie, maar dit het vir Roskam gegaan om die verdoeming van die staatsheleid wat hy as diskriminasie wou verwerp. Die onbetwiste ongelykheidsbehandelinge van blank en nie-blankes is gebaseer op die onbetwiste beskawingsverskille of -agterstand wat nie kan gelykop weeg nie. Dit is 'n beskawingsheerskappy wat in die verhouding van 'n Christelike voogdyskap, die nie-blanke tot beskawing en heskawingsverantwoordelikheid wil lei.

\section{iii. Veelheid van state.}

Roskam kan hom met 'n veelheid van state, Bantoetuislande nie versoen nie. Die lang pad van beskawingsontwikkeling, nie evolusionisties gesien nie, maar normatiewe ontwikkeling, val nie binne die wetenskaplike gesigsveld van die skrywer nie. Die oordrag van politieke en staatkundige verantwoordelikheid van die blanke aan die nie-blanke in sy eie gebied, word met allerlei onbewese vooroordele soos 'n klug, bedrog, swindelary, onsin, fantasie en 'n lugspieëling, doodgeskrywe.

Roskam wou diskriminasie bewys, daarom het hy die verhouding van 'n beskawingsongelykheid geïgnoreer, en die hele geïntegreerde situasie deur 'n gelykheidshril betrag. Die verhouding van Christelike voogdyskap is vir hom onderdrukking, daarom het hy in sy wetenskaplike ondersoek nie tot die watheidsgrond, die positiewe grondslag van apartheid deurgedring nie. Die opvoedkundige aspek van apartheid, die daadwerklike grondslag om die onbeskaafde Bantoe tot 'n selfstandige beskawing te lei, is wetenskajlik links gelaat. Die agterdog en vooroordele kan gemaklik tot sy voorveronderstelling van gelykheid herlei word. Die blanke heerskappy is vir Roskam afstootlik, diskriminasie, omdat hy nie aan 'n beskawingshcerskalppy in die huidige onmondige situasie van die Bantoe kan glo nie. Gehiedskeiding met 'n veelheid van state is 'n positiewe beleid wat die nie-blanke geleidelik tot beskawingsmondigheid wil lei. Hiervan verstaan Roskam niks.

\section{iv. Bantoetuislande.}

Die oordrag van politicke regte na die Bantoetuislande is vir Roskam 'n ewe groot onaanneemlikheid, omdat die humanistiese wetenskap sy waarheidswortel mis. Die onbewese gelykheidseis bly altyd dominerend, en die nasionale ontwikkeling van die etniese groepe volgens eie aard, geregverdige verskille word deur die humanisme verwerp, omdat hulle die ryke verskeidenheid in die skepping aan 'n valse eenheid en gelykheid wil opoffer. Die gedagte om die Bantoe in sy eie gebied op te voed, tot 'n ware nasionale, ontplooide, beskaafde Bantoe te lei, wat verantwoordelik- 
heid kan neem, is vir Roskam verfoeilik, omdat hy die gelykheid van state nie kan of wil begryp nie.

Die oordrag van politieke regte na die Bantoetuislande is vernederend, omdat hy die ongelyke verhouding in die luuidige situasie gelyk wil verklaar. Die nasionale ontsluiting van die etniese groepe word as vernederend gesien.

\section{v. Die ontwikkeling van Bantoetuislande.}

Die verantwoordelikheidsin van die Nasionale Regering om die Bantoetuislande te ontwikkel, en die oprigting van grensnywerhede, word met net soveel vooroordeel verwerp. Wanneer 'n wetenskaplike navorser die positiewe benadering van die geregverdigde ongelykheidsbehandeling met so 'n oppervlakkige ondersoek soos die van Roskam verwerp, dan word die beoefening van die wetenskap bedenklik. Apartheid is ' $n$ realistiese beleid van rasseskeiding wat die Bantoetuislande wil ontwikkel, en nog voordat daar 'n begin gemaak is, is dit al verwerp.

Die grensnywerhede wat moet dien as werkverskaffing aan die Bantoe word gesien as 'n daadwerklike poging om blanke heerskappy selfs in Bantoegebiede te handihaaf. Dit word vertolk as 'n loutere onwilligheid om die Bantoetuiste te ontwikkel, en die verklaring van dr. Verwoerd dat daar in die jaar 2000 nog meer as sesmiljoen Bantoes in blankegebiede sal wees, word gesien as 'n beplanning om die kwaadaardige blanke lieerskappy te kontinueer. Blanke verantwoordelikheid wat die onbeskaafde Bantoe wil versorg en to: beskawingsmondigheid wil lei, word as diskriminasie verwerp. Die wetenskapsbeoefening van Roskam laat veel te wense oor en moet as diskriminasie teen die blanke en die Christelike beskawing verwerp word.

Samevattende kritiek.

Roskam het hom in sy ondersoek by uitsprake en beleidsverklaring wat beslis op ongelykheid dui bepaal, en daarmee volgens die gelykheids dogma 'n sterk saak teen apartheid probeer uitmaak. Volgens sy voorveronderstellinge van 'n ongelyke behandeling van gelykes het hy sekerlik daarin geslaag om sy saak te bewys. Die ongelyke behandeling wat deur niemand ooit betwis is nie, is bewys, maar diskriminasie is nie bewys nie.

Sy humanistiese gelykheidsdogma het dit vir hom onmoontlik gemak om die beskawingsongelykheid na waarheid en waarde te kwalifiseer, en daarom is die positiewe beleid van apartheid op 'n onwetenskaplike wyse veroordeel, want daar is nie van alle waarheidsaspekte kennis geneem nie. Die wesenlike behoefte, die onbeskaafdheid en daarmee same- 
hangende die onontslote beskawingsverantwoordelikheid van die Bantoe, wat die positiewe beleid van apartheid wil aandurf, is opsetlik buite die gesigsveld van Roskam se wetenskapsbeoefening gelaat. Hy het hom op voorveronderstellings verlaat en die spoor van die wetenskap, die opspoor en opheldering van die waarheid, byster geraak.

Roskam het apartheid as ' $n$ beleid van Christelike voogdyskap verwerp, omdat hy kragtens sy humanistiese uitgangspunt nie in staat is om die Christelike verhouding van vader tot kind, voog tot onbeskaafde, blank tot nie-blank kan begryp nie. Hierdie wetenskaplike onmag lê ook aan die wortel van die dwaling dat hy die positiewe grondslag van apartheid nie kon begryp nie. Apartheid beteken die oordrag van regte en voorregte aan ' $n$ nasionale ontslote eenheid van die totale bevolking nadat daar 'n beskawingsmondigheid sigbaar is. Die oordrag van regte en voorregte kan slegs stelselmatig geskied, namate die verantwoordelikheidsin van die Bantoe onder invloed van die Christelike beskawing ontsluit het. 'n Bantoe Christelike beskawing is vir die humanisme onaanvaarbaar omdat hulle 'n beskawingsgelykheid veronderstel.

Apartheid as beleid van rasseskeiding is deur Roskam grondig bewys, maar apartheid as beleid van diskriminasie, ongelyke behandeling van gelykes, is beslis nie bewys nie, daarom is die diskriminasie-grondslag van die Suid-Afrikaanse samelewing nie bewys nie. Die onbewese gelykheidsdogma het die beskawingsongelykheid kragtens die deurwerking van die sondeval, buite die gesigsveld van sy ondersoek gelaat, en die positiewe grondslag van apartheid verloën, daarom rus sy studievrug op 'n wetenskaplike dwaling. Apartheid is nie 'n beleid van diskriminasie nie, maar 'n beleid van Christelike voogdyskap, 'n beleid of Christelike verantwoordelikheid om die onbeskaafde Bantoe tot 'n beskawingselfstandigheid te lei.

N. van Loggerenberg.

Benoni. 